\title{
Research on the Bearing Preload of Main Reducer of Rear Drive Automobile
}

\author{
Jianming Li and Xiaobin Wang \\ Hubei Communications Technical College, Wuhan, Hubei, PR China
}

\begin{abstract}
The structure characteristic of the main reducer of one rear drive automobile was introduced in this paper, and also the bearing preloads effect on the supporting stiffness of main reducer was discussed. Analyzed the calculation of bearing preload theoretically, and compared it with the simulation through ANSYS, which will give a design idea towards controlling of bearing preload.
\end{abstract}

\section{Keywords-main reducer; bearing preload}

\section{INTRODUCTION}

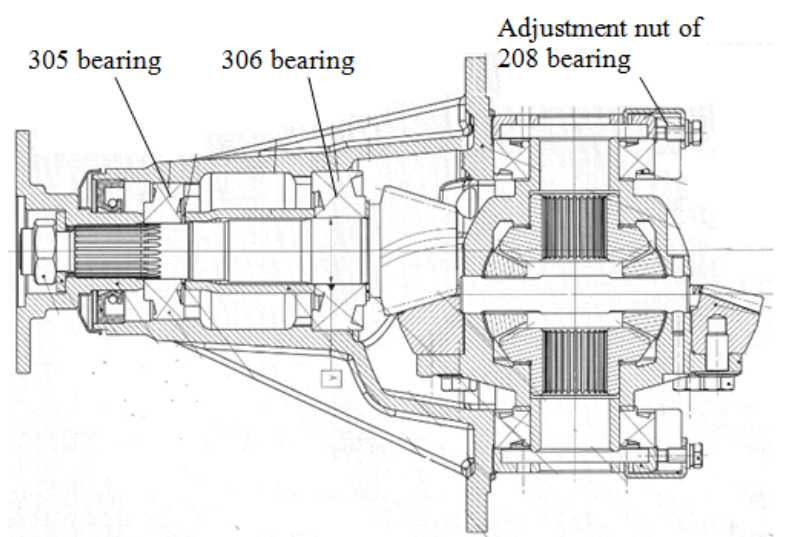

FIGURE I. STRUCTURAL MAP OF THE MAIN REDUCER OF ONE REAR DRIVE AUTOMOBILE

The theoretical research, related experience and utilization of rear drive automobile accumulated in the past years indicate that the hypoid gear pair of main reducer can ensure the transmission system has enough supporting stiffness that is an important factor to affect gear mesh and service life(1).The supporting stiffness must be taken into account when choose supporting way of gear transmission system, and it is strengthed through exerting preload to the bearing of main gear shaft during practice. The contact area between rolling element and raceway is increased after taking a preload to the bearing, as a result, the radical stiffness become bigger, which will ensure the proper mesh. Based on this, the gear will mesh more smoothly, causing little vibration when working. The driving bevel gear will drift axially and radically when the bearing preload is too small to ensure the supporting stiffness, which will cause the meshing position deviating from theoretical position, what's worse, it may produce vibration and noise, affecting the stability of gear drive. Another condition is that the bearing preload is too big, causing the clearance between the rolling element and raceway smaller, which will facilitate the gear overload working. As a result of this, the bearing will wear severely and reduce itself service life. To be worse, the bearing will work abnormally, causing NVH problems of main reducer, which may facilitate the rear axle lock and cause traffic accident(2).So, it is important to choose bearing preload, for it has a big effect on service life of the main reducer and NVH performance of the vehicle. This paper discussed the theoretical calculation of bearing preload and built ANSYS simulation model to analyze the preload. Compared with the two ways, it gets the method to calculate the bearing preload which will give a design idea towards controlling of bearing preload.

\section{Theoretical Calculation of Bearing Preload of MAIN REDUCER}

Nowadays, most bearing preload of main reducer in domestic manufactures is preloaded by the nut tightening machine and automatic gasket machine (3).The relative distance of the two bearing inner ring on the main gear shaft is measured by the automatic gasket machine, and then the proper size is chosen from a series of high-precision adjustment nut, after this, the nut is installed between the spacer and the bearing. Finally, the nut is tightened by the nut tightening machine, namely, the axial force $\mathrm{F}$ produced by the tightening action transferred to the bearing to preload the main reducer.

So, the bearing preload of main reducer has a direct correlation with tightening torque of nut of main gear(4).It is required to overcome two types of friction torque when exert tightening torque $\mathrm{T}$ to the locking nut. One is the friction resistance torque $T_{1}$ between contact area of screw pairs, and the other is the friction torque $T_{2}$ between the end face of nut and surface of the supporting member(5). So the tightening torque of main gear has the relationship with $T_{1}$ and $T_{2}$ as the formula (1) below.

$$
T=T_{1}+T_{2}
$$

The mechanical model of screw pairs can be simplified as a wedge, and its force analysis can be seen in figure 2 as below.

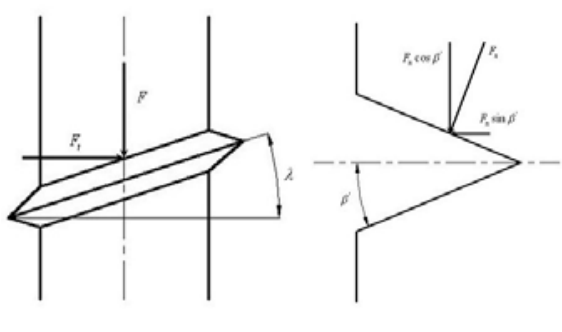

FIGURE II. FORCE OF SCREW 
The balance condition of each force along the spiral direction has the relationship as formula (2).

$$
F_{t} \cos \lambda-F \sin \lambda-\mu\left(F \cos \lambda+F_{t} \sin \lambda\right) / \cos \beta^{\prime}=0
$$

where $\lambda$ is spiral angle; $\mu$ is friction coefficient between the thread; $\beta$ is half of thread angle perpendicular to the section of helical.

$$
\text { To make } \frac{\mu}{\cos \beta^{\prime}}=\mu^{\prime}=\tan \rho \text {, where } F_{t}=\frac{2 T_{1}}{d_{2}} \text {, the }
$$

formula (2) can be simplified to formula (3).

$$
T_{1}=\frac{F d_{2} \tan (\lambda+\rho)}{2}
$$

where $d_{2}$ is the pitch; $\rho$ is the equivalent friction angle.

The supporting surface of the hex locknut is processed to a torus, and the friction torque to overcome the end face of nut and surface of the supporting member is as formula (4).

$$
T_{2}=\frac{\mu_{n} F \cdot\left(D_{1}^{3}-D_{0}^{3}\right)}{3\left(D_{1}^{2}-D_{0}^{2}\right)}
$$

where $\mu_{n}$ is the friction coefficient between the end face of nut and surface of the supporting member; $D_{1}$ is the outer diameter; $D_{0}$ is the inner diameter. So the tightening torque of main gear has the relationship as formula (5).

$$
T=F\left[\frac{d_{2} \tan (\lambda+\rho)}{2}+\frac{\mu_{n}\left(D_{1}^{3}-D_{0}^{3}\right)}{3\left(D_{1}^{2}-D_{0}^{2}\right)}\right]
$$

The researched tightening nut of driving bevel gear whose type is $\phi 18 \times 1.5-6 \mathrm{H}$ is general vee-thread. The related parameters of it can be seen from table1 .

TABLE I. VALUE OF RELATED PARAMETERS IN FORMULA(5)

\begin{tabular}{cccccccc}
\hline $\mathrm{d}$ & $\mathrm{P}$ & $\lambda$ & $\beta$ & $\rho$ & $D_{1}$ & $D_{0}$ & $\mu_{n}$ \\
\hline 18 & 1.5 & $60^{\circ}$ & $30^{\circ}$ & $6.59^{\circ}$ & 26 & 18 & 0.15 \\
\hline
\end{tabular}

Where $\mathrm{d}$ is the major diameter; $\mathrm{P}$ is the pitch; $\lambda$ is the helix angle; $\beta$ is the half of thread angle; $\rho$ is the equivalent friction angle; $D_{1}$ is the outer diameter of supporting surface; $D_{0}$ is the inner diameter; $\mu_{n}$ is the friction coefficient between the nut and supporting surface. Take these parameters to the formula(5).

$$
T=F\left[17.02575 \times \tan (1.606+6.59)+\frac{2 \times 0.15}{3} \cdot \frac{26^{3}-18^{3}}{26^{2}-18^{2}}\right]=0.0028943 F
$$

As the tightening torque exerted to the locking nut when the main reducer is being assembling in this subject is between 200N.m and 250N.m,the minimum and maximum axial preload produced by the locking nut can be calculated as the computation procedures below.

$$
\begin{aligned}
& F_{\text {min }}=200 / 0.0028943=69101.34 \mathrm{~N} \\
& F_{\text {max }}=250 / 0.0028943=86376.67 \mathrm{~N}
\end{aligned}
$$

\section{III. SimUlATION ANALYSIS OF BEARING PRELOAD}

\section{A. Stress Analysis of Bearing Preload of the Main Reducer}

The locking nut will generate a torque at the effect of the tightening torque after the assembly of main reducer. As the wedge principle, it will produce an axial force, which will transfer from the flange to the inner ring of 305bearing. This force can exert its effect to two paths, one is to the bearing outer ring, and the other is to the adjustment shim that will then transfer from the spacer to the inner ring of 306 bearing. Finally the force accumulated from the above two paths will transfer from the adjustment shim to the driving bevel gear. The concrete transfer path can be seen from figure 3 as below.

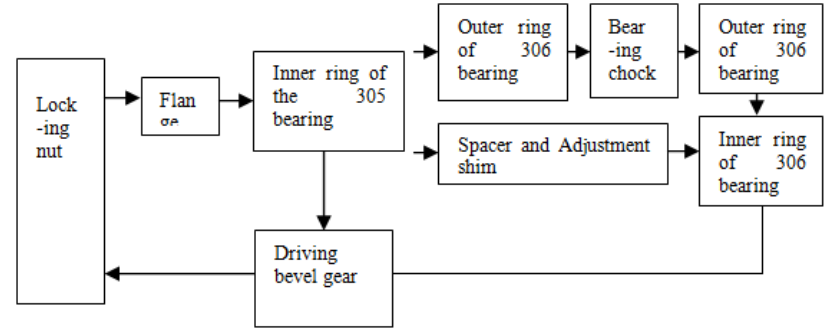

FIGURE III. CLOSED SYSTEM SKETCH OF AXIAL FORCE OF MAIN REDUCER

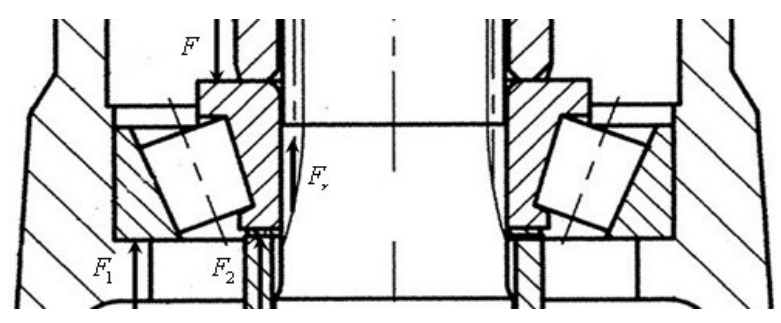

FIGURE IV. FORCE SCHEME OF BEARING OF MAIN REDUCER

The $\mathrm{F}$ in the above figure is axial preload; $F_{1}$ is the force that bearing chock of shell of main reducer to the outer ring of 305bearing; $F_{2}$ is the force that spacer to the inner ring of 305bearing; $F_{3}$ is the axial friction that inner ring of 305bearing to the main gear shaft. From the force scheme, the distribution relationship of axial preload of the bearing can be described as the formula (6).

$$
F=F_{1}+F_{2}+F_{3}
$$




\section{B. Modeling of the Simulation}

The main gear shaft, shell of main reducer and flange has a direct correlation with bearing force in the structure of the main reducer. The respective function of the three parts is as below. The shell of main reducer can fix the outer ring of bearing, and it can be neglected when modeling. The flange can transfer the axial force to the inner ring of bearing under the action of tightening torque, and it can be simplified as the external load. The main gear shaft and bearing is connected with the spacer and adjustment shim, which has the function of reaction, and can be treated as a balance force exerting to the inner ring of the bearing. In conclusion, the force scheme of bearing can be simplified as shown in figure5.

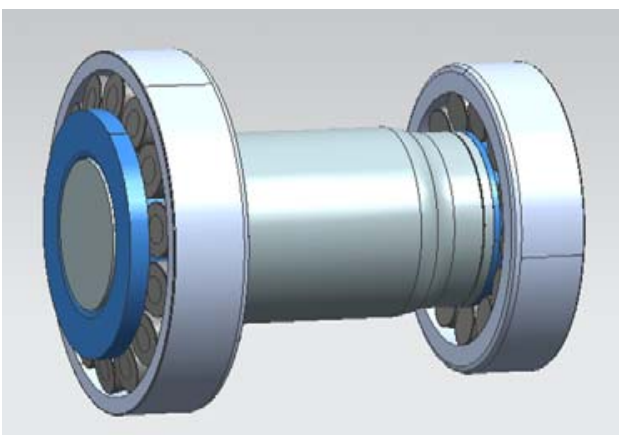

FIGURE V. SIMPLIFIED MODEL OF MAIN REDUCER

These papers mainly do research on the stress and strain of inner and outer ring of bearing, spacer, adjustment shim and main gear shaft under the bearing preload. Choose the element type SOLID45 in ANSYS, and it has 8 nodes and 3 freedoms. Set the material type as the SOLID95, which has 20 nodes, and it can simulate the complicated surfaces in a better algorithm. The rolling element number of the two tapered roller bearing is 16 and 17, so the FE model in figure7 is1/32 and 1/34 compared to the realistic model. Set the flexible contact between the raceway of inner and outer ring of bearing and the surface of ball, and the surface of outer ring of bearing and surface of gear shaft. The outer surface of bearing is set to completely restraint. The thickness range of adjustment shim of researched main reducer is between 1.8 and $2.2 \mathrm{~mm}$. This paper chose $2 \mathrm{~mm}$, and set the tightening torque $200 \mathrm{~N}$.m. The surface area of the inner ring of 305 bearing is $3.167 \mathrm{~m}^{2}$, and get the surface load, whose value is $63.27 \mathrm{MPa}$. Similarly, the surface load of 306beaing is $83.17 \mathrm{MPa}$.

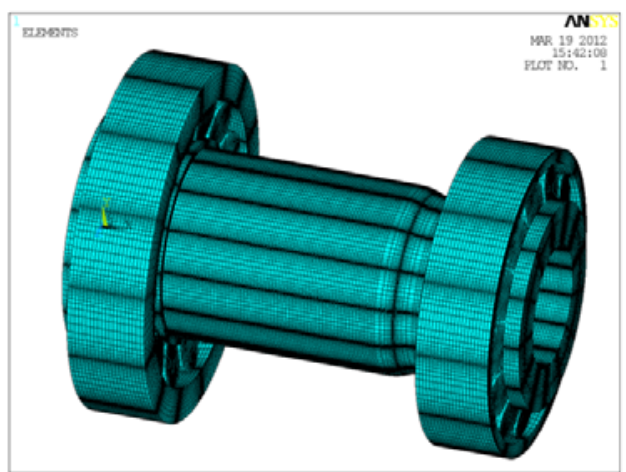

FIGURE VI. SIMPLIFIED MESH MODEL OF MAIN REDUCER

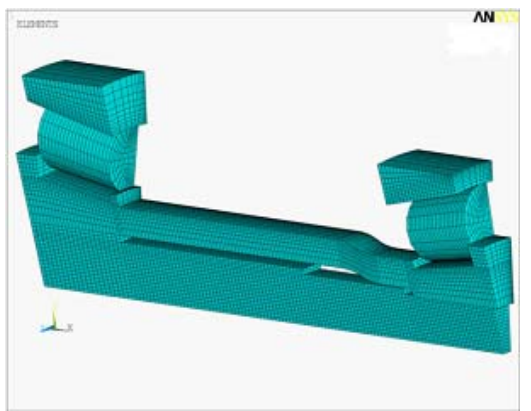

FIGURE VII. FE MODEL OF MAIN REDUCER

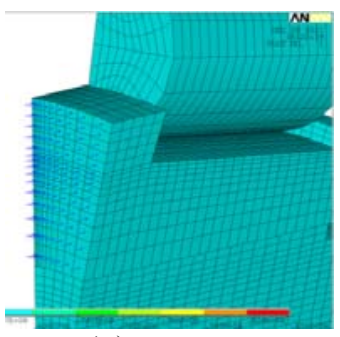

(a) 305bearing

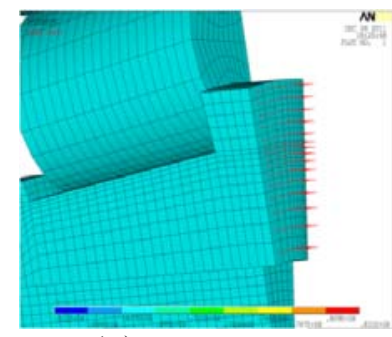

(b) 306bearing
FIGURE VIII. FORCE LOAD OF BEARING

\section{Ansys Finite Element Analysis}

Get the nephogram shown in figure 9 after post-processing.

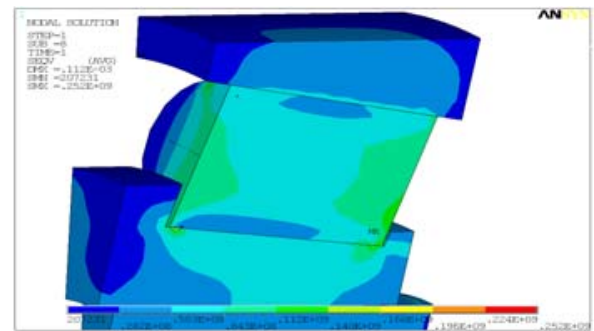

(a) Stress - strain diagram of 305bearing

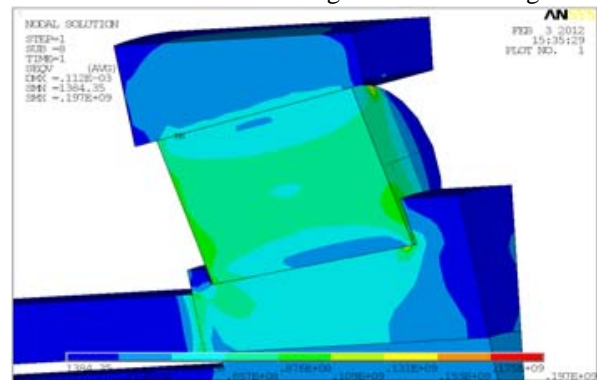

(b) Stress - strain diagram of 306bearing

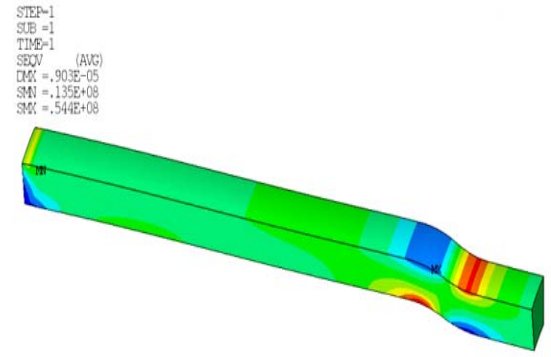

(c) Stress - strain diagram of spacer

FIGURE IX. STRESS - STRAIN DIAGRAM OF BEARING 
From the FE analysis, the maximum stress of 305bearing occurs at the end of the rolling element, and the value is $252 \mathrm{MPa}$, the corresponding displacement is $0.112 \mathrm{~mm}$. The maximum stress and corresponding displacement of 306bearing is $197 \mathrm{MPa}$ and $0.112 \mathrm{~mm}$. The stress at the two end of spacer is $33.9 \mathrm{MPa}$, and the maximum stress occurs at fillet, whose value is $54.4 \mathrm{MPa}$.

Get the reaction of the outer ring of 305bearing and end face of the spacer through ANSYS. The value is $324.96 \mathrm{~N}$ and $1807.7 \mathrm{~N}$, as the simulation model is $1 / 32$ of the realistic model, so the really force is as below.

$$
\left\{\begin{array}{l}
F_{1}=324.69 \times 32=10390.08 N \\
F_{2}=1807.7 \times 32=57846.4 N
\end{array}\right.
$$

The maximum stress is $54.4 \mathrm{MPa}$, and the axial force can be calculated through the section area of supporting spacer whose value is $7366.14 \mathrm{~N}$.The friction produced by the interference fit of the inner ring of bearing and shaft is the normal stress at the connection of inner ring of bearing and shaft divides the contact area. From the FE analysis, the maximum contact stress $P_{f}$ occurs at the region of interference fit, and the corresponding value is $2.94 \times 10^{7} \mathrm{~Pa}$. According to the related parameters of the bearing, the friction produced by the inner ring of 305bearing and shaft can be calculated as below.

$F_{r}=2 \pi b h f P_{f}=2 \pi \times 12.5 \times 10^{-3} \times 17 \times 10^{-3} \times 0.05 \times 2.94 \times 10^{7}=1982.5 N$

$\mathrm{b}$ is the radius of inner ring of bearing;

$\mathrm{h}$ is the width;

$\mathrm{f}$ is the friction factor.

So the bearing preload is $70218.98 \mathrm{~N}$, which can be calculated from the formula (6). Compared with the theoretical calculation result, namely $69206.5 \mathrm{~N}$ and the error is $1.5 \%$, which indicated that the FE analysis has a reliable persuasion.

\section{CONCLUSION}

The parametrical finite model of main reducer built in this paper has a higher accurate degree compared with the theoretical result, which indicates that the value analyzed from FE model is reliable. Besides, the way used to calculate the bearing preload in this paper is verified, and it is significant and useful.

\section{REFERENCES}

[1] Du Bing, Liu Dengfa. Research on bearing preload of main reducer of light off-road vehicle [J].Mechanical Engineer, 2007,11:48-49.

[2] Zhou Jianguo. Assembles craft of car rear axle and noise detection and fault diagnoses[D].Chengdu:Sichuan University,2005.

[3] Cheng Jianqiang,Xu Baohua,Xie Pei.Digital assembly of main reducer of rear axle of light vehicle [J].Equipment Manufacturing Technology, 2011,11:106-109.

[4] Fan Yunsheng,Guo Chen,Zhou Shouming.Evaluation of tightening nut machine of driving bevel gear based on model [J]. Chinese Journal of Scientific Instrument,2011,06:1433-1440.

[5] Song Rongsheng. Experimental analysis of axial preload connected by thread[J].Tianjin Institute of Technology,2001,S1:23-24. 